\title{
Splintered Memories or Vivid Landmarks? Qualities and Organization of Traumatic Memories with and Without PTSD
}

\author{
DORTHE BERNTSEN $^{1} *$, MORTEN WILLERT ${ }^{1}$ \\ and DAVID C. RUBIN ${ }^{2}$ \\ ${ }^{1}$ University of Aarhus, Denmark \\ ${ }^{2}$ Duke University, USA
}

\begin{abstract}
SUMMARY
One hundred and eighty-one students answered a standardized questionnaire on Post-Traumatic Stress Disorder (PTSD): 25 reported trauma(s) and indicated a pattern of after-effects that matched a PTSD symptom profile, whereas 88 indicated trauma(s) but no PTSD symptom profile. Both groups answered a questionnaire addressing the recollective quality, integration and coherence of the traumatic memory that currently affected them most. Participants with a PTSD symptom profile reported more vivid recollection of emotion and sensory impressions. They reported more observer perspective in the memory (seeing themselves 'from the outside'), but no more fragmentation. They also agreed more with the statement that the trauma had become part of their identity, and perceived more thematic connections between the trauma and current events in their lives. The two groups showed different patterns of correlations which indicated different coping styles. Overall, the findings suggest that traumas form dysfunctional reference points for the organization of other personal memories in people with PTSD symptoms, leading to fluctuations between vivid intrusions and avoidance. Copyright (C) 2003 John Wiley \& Sons, Ltd.
\end{abstract}

A traumatic experience, almost by definition, violates a person's expectations and contradicts well-established schematized knowledge of the self and the world (Janoff-Bulman, 1988). As a consequence, traumatic experiences may be hard to process and integrate with prior knowledge. Many clinical theories of Post-Traumatic Stress Disorder (PTSD) take their starting point in this phenomenology of real-life traumas and describe PTSD as a disorder of autobiographical memory, in which the trauma memory does not form a coherent narrative and is not integrated into the overall life story of the person (e.g. Brewin et al., 1996; Horowitz, 1975; Horowitz \& Reidbord, 1992; Nijenhuis \& van der Hart, 1999; Van der Kolk \& Fisler, 1995). Memory mechanisms specific to traumas are often invoked to describe the disintegration. After a brief review of such theories, we argue that the evidence for their claims is weak. Based on findings from the experimental memory literature we

\footnotetext{
*Correspondence to: Dorthe Berntsen, Institute of Psychology, University of Aarhus, Asylvej 4, 8240 Risskov, Denmark. E-mail: dorthe @ psy.au.dk

Contract grant/sponsor: Danish Research Council for the Humanities.
} 
propose an alternative framework for the organization of trauma memories in PTSD. Assumptions derived from this framework and the clinical literature are examined in a study on the organization and recollective qualities of trauma memories among persons with and without a PTSD symptom profile. We use the PTSD criteria in the DSM IV (American Psychiatric Association, 1994) to isolate persons with a PTSD symptom profile from persons without.

\section{THE DISINTEGRATION VIEW OF TRAUMA MEMORIES IN PTSD}

Many theories describe PTSD as a disorder in autobiographical memory and emphasize schema violation and incomplete processing of the traumatic event in the development of PTSD. In this view, trauma memories are fragmentated, poorly integrated in the person's life story and processed in ways that render them distinct from other autobiographical memories. For example, Horowitz (1975) describes intrusions and repetitive thoughts following a traumatic event with reference to the Zeigarnik effect (better memory for uncompleted tasks). He proposes an 'active memory storage' (p. 1462) — a part of longterm memory with an inherent tendency at repeating its own content until processing is completed. Thus, in this account, the lack of integration of the trauma with prior knowledge leads to increased accessibility of the trauma memory, maintained by a special memory storage from which intrusions and repetitive thoughts arise. At an emotional level, this increased access is paralleled by efforts at avoiding conscious recollections of the trauma, leading to a fluctuation between intrusive memories and avoidance (see also Horowitz, 1986; Horowitz \& Reidbord, 1992).

Brewin et al. (1996) propose a dual-memory system according to which parts of the trauma are accessible for deliberate conscious retrieval (verbally accessible memories) whereas other parts are accessible only in response to concrete situational cues (situationally accessible memories). Verbally accessible memories are partly reconstructed versions of the original trauma, involving relatively little reliving of original emotion and sensory details as compared to situationally accessible memories, involving emotionally powerful flashbacks of the trauma (see Ehlers \& Clark, 2000, for a similar distinction between associative and intentional memory processes in relation to traumas). In this theory, the lack of cognitive integration responsible for the development of PTSD is between both the situationally and verbally accessible versions of the traumatic memory and between the trauma and the person's other memories and sense of self.

In some theories, the cognitive disintegration is labeled dissociation. This concept goes back to Pierre Janet, a French-nineteenth century psychiatrist (Nemiah, 1998). Three different forms of dissociation are distinguished (e.g. van der Hart et al., 1998). Only claims related to two of them are relevant here. Primary dissociation refers to a disintegration of the autobiographical memory of the trauma. Some sensory and affective components of the original traumatic event may be isolated and inaccessible for conscious retrieval, whereas other sensory details may be highly salient and vividly relived. The person's thoughts and verbal description of the trauma memory does not form a coherent narrative (e.g. Nijenhuis \& van der Hart, 1999). Secondary dissociation refers to a disintegrated state of mind at the time of the trauma, which separates the person from his or her own emotional reactions. One frequently mentioned example is the so-called out-of-the-body experience: The person feels that he or she is mentally leaving his or her own body and observing the event from a distance (e.g. van der Hart et al., 1998). 


\section{Evidence for the disintegration view}

Evidence for the disintegration view largely comes from clinical observations on the phenomenology of traumatic memories. Our review of the clinical findings follows Ehlers and Clarke's (2000) summary. We argue that once these findings are compared with findings on the phenomenology of autobiographical memories in general, it is no longer clear that trauma memories are fragmentated, disintegrated and involve special memory processes.

\section{Involuntary memories}

It is often observed that trauma memories come to mind unbidden (e.g. Ehlers \& Clarke, 2000). However, involuntary memories are not limited to traumas or even to emotionally negative events. A great variety of autobiographical memories (including highly positive ones) are reported in diary studies of involuntary memories (Berntsen, 1996, 2001; see also Brewin, et al., 1996). Ehlers and Clark (2000) observe that involuntary trauma memories seem to be more complete and to involve more sensory and emotional reliving at retrieval. However, similar differences have been found in studies comparing involuntary and voluntary non-traumatic memories (Berntsen, 1998; Berntsen \& Hall, presentation at the 3rd international conference on memory, Valcncia, July 2001). Ehlers and Clark (2000) further observe that involuntary trauma memories are often triggered by cues 'that do not have a strong semantic relationship to the traumatic event' (p. 325). The same is true for involuntary memories of non-traumatic autobiographical events (Berntsen, 1996, 1998).

\section{Sensory reliving}

Ehlers and Clark (2000) observe that the conscious memory of the trauma consists mainly of sensory impressions, especially vision, rather than of thoughts. The sensory impressions are appreciated by the rememberer as if they are 'happening right now' (p. 324). However, these characteristics are not specific to trauma memories but apply to autobiographical memories in general, according to Brewer's (1996) review of the psychological and philosophical literature on this issue (see also Wheeler et al., 1997). Recent empirical studies document that the retrieval of autobiographical memories involves 'reliving' of sensory (especially visual) impressions associated with the original event and some feeling of travelling in time (Johnson, 1988; Larsen, 1998; Rubin et al., Unpublished manuscript, 2002).

\section{Fragmentation}

It is often claimed that intentionally recalled trauma memories form poorly structured narratives. Brewin (2001) summarizes this view: 'conscious or 'verbally accessible' memories of trauma will tend to be vague, poorly organized, and to show gaps and discontinuities' (p. 161; see also Ehlers \& Clark, 2000; van der Kolk \& Fisler, 1995). While this view is widespread, the evidence for it is surprisingly weak. We have been able to locate only a few studies. Tromp et al., (1995) found that rape memories were less vivid and less detailed than memories for other sorts of unpleasant experiences. Unfortunately, Tromp et al. did not report the event age of the different kinds of the memories, for which reason the findings could reflect differences in the length of retention. Van der Kolk and Fisler (1995) compared recollective qualities of traumatic and non-traumatic autobiographical memories among persons who 'were haunted by memories of terrible life experiences' (p. 514). While most of their participants (89\%) were able to tell a coherent narrative about the traumatic experience at the time of the interview, all of their participants claimed that immediately after the trauma they had been unable to do so. 
The study used retrospective assessments, which are a questionable method for obtaining phenomenological reports (Ericsson \& Simon, 1993). Also, the study suffers from the lack of a control group to assess what people without PTSD would report. Foa, et al. (1995) compared rape memories before and after exposure therapy and found that a reduction in the fragmentation in the organization of the narrative was positively related to a reduction in the level of trauma-related anxiety. However, it is not clear whether fragmentation of the articulated narrative (operationalized as repetitions, unfinished thoughts and speech fillers) reflects fragmentation in the memory as opposed to practice in telling the memory. Amir et al. (1998) measured the reading level of rape narratives and found that reading level correlated negatively with PTSD symptoms twelve weeks, but not two weeks, after the trauma. Again, the relation between reading level and memory organization is unclear.

\section{Out-of-the-body perspective}

Another possible component of the phenomenal quality of traumatic memories is the socalled 'out-of-the-body' experience. When the person reflects back upon the event, it seems to him or her that he or she did nor originally perceive what happened from his or her own position, but from a vantage point external to the body (van der Hart et al., 1998).

Historically, such memories were observed by Freud (1899/1953). More recent evidence shows that 'out-of-the-body' perspective is not specific to traumatic memories. Nigro and Neisser (1983) found that field memories (remembering from the vantage point of the self) were only slightly more common than observer memories (remembering from an external vantage point). In a replication, Frank and Gilovich (1989) found that frequency of observer memories increased with event age. Though most memories appear to have a preferred perspective, this is not fixed and can be varied at will, according to Nigro and Neisser (1983). They found that the person's purpose in recalling the event influenced the perspective from which the event was recalled. Recollecting (reliving) emotions at retrieval was associated with field memories. Thus, a person who tried to recollect (or relive) his or her emotions might deliberately choose a field perspective to achieve this goal. Though not explicitly mentioned by Nigro and Neisser, the logical consequence seems to be that an observer memory of an emotional event may be a way of avoiding, or at least reducing, reliving of strong emotions during recollection of the trauma. This is supported by Robinson and Swanson (1993) who found that a shift from field to observer memories was associated with reduced affect. Thus, one conclusion that can be drawn from the modern experimental literature on the topic appears in many ways similar to the one originally suggested by Freud and by current clinical theories: observer ('out-of-the-body') memories may be used to distance the remembering person from unpleasant past experiences. This mechanism is not specific to memories of trauma.

\section{THE LANDMARK VIEW OF TRAUMA MEMORIES IN PTSD}

A radical alternative to the disintegration view can be derived from the non-clinical literature on autobiographical memory. Many studies of autobiographical memory document that emotional arousal improves, rather than impairs, memory (see overview by Brewer, 1992) though sometimes only for the central details of the event (see Christianson,1992, for a review). Instead of leading to disintegration, highly emotional and (thus) distinctive events may help to keep the autobiography integrated by forming reference points for the organization of other less distinctive events (Neisser, 1982; Pillemer et al., 1988; 
Robinson, 1992; Rubin \& Kozin, 1984; Shum, 1998). Consistent with this view, Berntsen (2001) argued that traumatic memories are likely to form multiple links to other memories in the autobiographical knowledge base and thereby become reference points for the attribution of autobiographical meaning to less distinctive experiences and for generating expectations. While this mechanism is functional in the case of important, non-traumatic memories - such as weddings, graduations, journeys etc. - it is likely to be dysfunctional in the case of a trauma, as in this case, a highly negative, perhaps rare, uncontrollable and partly incomprehensible event will govern the attribution of meaning to other personal experiences. In this explanation, the crucial difference between persons with PTSD and persons with traumas but no PTSD is the degree to which the traumatic memory has formed a landmark in the organization of autobiographical memory, with a continuous impact on the interpretation of new experiences and the development of expectations for the future. One likely outcome of such a landmark memory may be 'a sense of serious current threat' which is considered to be an indispensable characteristic of PTSD by Ehlers and Clark (2000, p. 320). Also, the increased accessibility associated with landmark memories can explain rumination and also why rumination seems to worsen PTSD. Rumination rehearses the trauma memory and thus increases its accessibility and prolongs its status as a landmark. Increased access may also explain why trauma memories often come to mind unbidden.

\section{Evidence for the landmark view}

Studies of the memory of concentration camp survivors from World War II show that trauma memories can remain accurate and detailed even after 45 years (Schelach \& Nachson, 2001; Wagenar \& Groeneweg, 1990). In their study of Auschwitz survivors, Schelach and Nachson (2001) found that emotional events were remembered more accurately than neutral events and that survivors' narratives were judged to be clear, vivid, detailed, orderly, easy to comprehend and realistic. We do not know whether these survivors had PTSD and, if so, whether their memories deviated from concentration camp survivors with no PTSD. Nevertheless, the findings suggest that negative emotional stress is associated with enhanced rather than impaired memory.

In a diary study of involuntary memories among persons with a PTSD symptom profile, Berntsen (2001) found that participants often classified non-traumatic memories as thematically or causally related to their most traumatic experience. McNally et al. (1995) examined autobiographical memory among Vietnam veterans with and without PTSD. Among the veterans with PTSD, they unexpectedly identified a subgroup who were still wearing their Vietnam regalia (e.g. combat medals, fatigues, POW/MIA buttons). McNally et al. considered this behavior as an indication of being psychologically 'still in Vietnam' - or, in the words that we would prefer here, the combat experiences formed a central part of these individuals' identity and self-understanding. Consistent with the landmark view, McNally et al. found that the regalia group recorded more memories from their time in Vietnam when cued by both positive and negative cue-words than did the controls and the individuals with PTSD who were not wearing regalia.

\section{HYPOTHESES FOR THE PRESENT STUDY}

According to the landmark view, we should expect individuals with PTSD to recollect their trauma experiences more vividly and with more narrative coherence than individuals who report traumas without showing a PTSD symptom profile. We should also expect 
individuals with a PTSD symptom profile to consider the traumatic experience as more central to their personal identity than individuals without a PTSD symptom profile. Similarly, the former is expected to perceive more connections between the traumatic memory and experiences in their present life than the latter.

In the disintegration view, on the other hand, individuals with PTSD have more fragmentated (less coherent) trauma memories than individuals without. Furthermore, while parts of the trauma memory may be vividly recollected, other parts are impaired due to incomplete processing. This means that when averaging across more sensory specific measures from many persons, individuals with PTSD may on average have less vivid recollections of their trauma than persons without a PTSD sympotom profile. Individuals with a PTSD symptom profile should consider the traumatic experience as less central to their personal identity and perceive fewer connections between the traumatic memory and experiences in their present life than individuals who report traumas without showing a PTSD symptom profile.

Finally, according to both the landmark view and the disintegration view, we should expect more observer perspective among individuals with a PTSD symptom profile.

\section{METHOD}

The study investigates characteristics of traumatic autobiographical memories in a nonclinical population. It examines the recollective qualities and narrative coherence of trauma memories among traumatized persons with and without a PTSD symptom profile. A PTSD symptom profile is here defined as specific patterns of mental after-effects from a traumatic experience that match the formal criteria for PTSD (American Psychiatric Association, 1994)

\section{Participants}

A total of 181 persons participated: 122 Danish psychology students (mean age 28 years, $S D=5.9,103$ females) participated as part of a teaching course, and 59 Danish folk high school students (mean age 22 years, $S D=3.8,40$ females) participated during a general lecture on psychology at the folk high school. All participants were explicitly allowed to give in blank questionnaires or to leave after the introduction if they did not want to participate. All responses were anonymous. After data collection, all participants were informed about PTSD and autobiographical memory, and the most important ideas behind the questionnaires were described. They were encouraged to comment and ask questions. If needed, they could stay and talk individually with the experimenter.

\section{Procedure}

Participants filled in a questionnaire consisting of two parts. The first part was a translated Danish version of the Posttraumatic Stress Diagnostic Scale (PDS; Foa, 1995), which is a standardized, clinical questionnaire used to detect PTSD in populations at risk for developing this disorder. The questionnaire was slightly modified in that we measured the age of the traumatic event in months and years.

Briefly, the questionnaire inquired whether the person had ever had a traumatic experience (a checklist of possible traumas was offered) and, if so, whether the person 
was still influenced by the traumatic event. If the person reported more than one traumatic experience, answers should concern the one that currently bothered him or her most. Questions pursued were.

(1) Objective characteristics of the traumatic event-e.g. whether it had involved physical injury and been life threatening

(2) Emotional characteristics of the traumatic event-e.g. whether the person had felt helpless and terrified

(3) Time since the trauma measured in years or (if less than a year ago) in months

(4) Effects in terms of reexperiencing symptoms - e.g. to what extent the person suffered from intrusive memories and flashback about the trauma

(5) After-effects in terms of avoidance symptoms - e.g. to what extent the person tried to avoid thinking about the experience

(6) After-effects in terms of arousal symptoms-e.g. to what extent the person had trouble concentrating or falling asleep at night, and

(7) The person's overall psychological distress in everyday life due to the trauma.

For each category of after-effects, the person indicated the frequency within the most recent month.

The second part was a questionnaire developed for the purpose of the present study. It examined the autobiographical memory of the trauma, by addressing the recollective quality of the conscious memory, the way participants coped with the traumatic memory and the coherence and integration of the traumatic memory in the overall life story and personal identity. Ratings given while an activity is ongoing reflect the cognitive processes involved in that activity in ways that relate in reasonable ways to objective measures (Ericsson \& Simon, 1993). We therefore obtained the ratings on recollective quality while our participants were being asked to recall their trauma memory. An English version of this questionnaire is presented in the Appendix.

\section{RESULTS}

One hundred and thirteen participants (62\%) reported at least one traumatic event corresponding to the description of a traumatic event in the DSM IV, criterion A1 (American Psychiatric Association, 1994), which had occurred at least a month ago. Forty-two reported more than just one trauma. A total of 186 traumas were reported. The traumas that currently bothered our participants most were accidents (21\%), lifethreatening diseases $(13 \%)$, combat experiences $(5 \%)$, violent assaults $(5 \%)$, natural disasters $(5 \%)$ sexual assaults (4\%), imprisonment (1\%). A substantial amount of 'other' traumas was reported $(46 \%)$; that is, traumas that were not offered as options on the checklist on the PDS questionnaire, such as suicide or suicide attempts, deaths of parents, serious neglect or rejections. When each of these categories was compared to the remaining cases on the prevalence of a PTSD symptom profile (to be described later), there were no significant differences according to a series of Fisher exact tests.

We sorted the 113 participants who reported at least one trauma into a PTSD symptom profile group and a non-symptom profile group, based on citeria A1, B, C, D, E, and F in the DSM IV. That is, to be included in the PTSD symptom profile group, participants should report at least one re-experience symptom, at least three avoidance symptoms, at least two arousal symptoms. The duration of the symptoms should have been at least a 
month and should cause distress or impairment in everyday functioning. Because we wanted to examine possible differences between the two groups on reported fear and helplessness at the time of the traumatic event, we did not include this variable in our initial classification. However, it turned out that all our 25 participants who met the criteria A1, B, C, D, E, and F also reported either intense fear or helplessness at the time of the trauma. In short, the PTSD symptom profile group satisfied all the criteria for PTSD described in the DSM IV (American Psychiatric Association, 1994).

The groups with and without a PTSD symptom profile did not differ with respect to the age or gender of participants. However, 9 of the 25 participants in the symptom profile group versus 14 of $84^{1}$ participants in the other group had received therapeutic treatment for their trauma $\left(\chi^{2}(1)=4.33, p<0.05\right)$. Possible effects of therapy in relation to the present findings will be addressed more carefully in the subsequent analyses. The first part of the results section addresses differences between the mean scores in the PTSD symptom profile versus the non-PTSD symptom profile group. The second part explores similarities and differences between correlations within the two groups.

\section{Means}

A number of differences were found between the mean scores of participants with a PTSD symptom profile and participants without. These differences relate to (1) characteristics of the original traumatic experience, (2) recollective qualities associated with the traumatic memory at retrieval and (3) the integration of the memory with the life story and coping strategies.

\section{Characteristics of the original traumatic experience}

Table 1 shows characteristics of the traumatic event and total number of reported traumas in the two groups. Persons with a PTSD symptom profile reported more traumas (including the one that currently bothered them most and upon which they therefore based their answers to the questionnaire). They reported a more emotional reaction (of fear and helplessness) during the traumatic event. No significant differences were found between the two groups on severity of the traumatic event - that is, whether the participant or somebody else was physically injured, and whether the participant or someone else had been in life danger. The groups did not differ significantly as to whether the traumatic event had violated the person's basic expectations, nor on the age (measured in months) of the traumatic events (contrary to expectations derived from studies on ordinary forgetting).

Table 1. Characteristics of the traumatic event and number of reported traumas in the PTSD symptom profile group and the non-PTSD symptom profile group

\begin{tabular}{|c|c|c|c|c|c|c|c|}
\hline & \multicolumn{2}{|c|}{$\begin{array}{l}\text { PTSD symptom } \\
\text { profile }\end{array}$} & \multicolumn{2}{|c|}{$\begin{array}{l}\text { Non-PTSD } \\
\text { symptom profile }\end{array}$} & \multicolumn{3}{|c|}{$t$-tests } \\
\hline & $M$ & $S D$ & $M$ & $S D$ & $d f$ & $t$ & $p$ \\
\hline Reported traumas & 2.24 & 1.69 & 1.47 & 0.87 & 111 & 3.06 & $<0.001$ \\
\hline Emotion score & 1.88 & 0.33 & 1.29 & 0.78 & 109 & 3.67 & $<0.001$ \\
\hline Trauma severity & 1.12 & 0.94 & 1.37 & 0.93 & 108 & 1.20 & $=0.23$ \\
\hline Unexpectedness & 4.01 & 1.19 & 4.08 & 1.35 & 105 & 1.08 & $=0.24$ \\
\hline Months ago & 82.00 & 65.53 & 66.91 & 66.70 & 103 & 0.97 & $=0.33$ \\
\hline
\end{tabular}

${ }^{1}$ Four cases with missing data were excluded from this analysis. 
Table 2. Recollective qualities associated with the trauma memory in the PTSD symptom profile group and the non-PTSD symptom profile group

\begin{tabular}{|c|c|c|c|c|c|c|c|}
\hline & \multicolumn{2}{|c|}{$\begin{array}{l}\text { PTSD symptom } \\
\text { profile }\end{array}$} & \multicolumn{2}{|c|}{$\begin{array}{c}\text { Non-PTSD } \\
\text { symptom profile }\end{array}$} & \multicolumn{3}{|c|}{$t$-tests } \\
\hline & $M$ & $S D$ & $M$ & $S D$ & $d f$ & $t$ & $p$ \\
\hline Observer view & 3.20 & 1.40 & 1.89 & 1.29 & 101 & 3.77 & $<0.001$ \\
\hline Field view & 3.20 & 1.29 & 4.16 & 1.16 & 102 & 3.53 & $<0.001$ \\
\hline Emotion & 3.72 & 1.02 & 2.77 & 1.15 & 104 & 3.67 & $<0.001$ \\
\hline Smell-taste & 2.44 & 1.33 & 1.81 & 1.18 & 104 & 2.24 & $<0.05$ \\
\hline Travel in time & 3.40 & 1.15 & 2.76 & 1.25 & 104 & 2.24 & $<0.05$ \\
\hline Bodily & 3.44 & 1.38 & 2.77 & 1.19 & 104 & 2.16 & $<0.05$ \\
\hline Audition & 3.12 & 1.42 & 2.50 & 1.42 & 104 & 1.89 & $=0.06$ \\
\hline Vision & 3.64 & 1.08 & 3.17 & 1.24 & 105 & 1.71 & $=0.09$ \\
\hline Like a video & 3.17 & 1.34 & 2.79 & 1.33 & 103 & 1.21 & $=0.23$ \\
\hline Coherence & 3.25 & 1.30 & 3.25 & 1.39 & 102 & 0.00 & $=1.00$ \\
\hline
\end{tabular}

Recollective qualities associated with the traumatic memory

Table 2 shows that participants with PTSD symptom profile had higher recollection scores. Among these are differences in emotion, smell-taste, bodily sensations and feeling of travelling in time. Although ratings of audition and vision did not differ significantly between the two groups, a trend was found in the same directions as for the other measures of sensory reliving. Consistent with the disintegration and landmark views, participants with PTSD symptom profile reported more observer and, reversely, less field perspective in their memory than the non-PTSD symptom profile group. Contrary to the disintegration view, the PTSD profile group did not rate their memory as less coherent than the non-PTSD profile group.

To control for possible biases due to the fact that more persons in the PTSD symptom profile group had received therapeutic treatment in relation to the trauma, a series of multiple regression analyses was conducted. Each analysis included one of the variables listed in Table 2 as the dependent variable. Independent variables were PTSD symptom profile $(y / n)$ and therapy $(y / n)$. In none of these analyses was therapy a significant predictor, whereas PTSD symptom profile was a significant predictor for the first six variables included in Table 2, and tended to be significant for audition and vision, consistent with the results presented in Table 2.

\section{The role of the traumatic memory in the lifestory}

Table 3 shows that participants with a PTSD symptom profile perceived more connections and similarities between the trauma and current experiences in their life than participants without, and they agreed more with the statement that the trauma had become part of their identity. Both observations conflict with the idea that the trauma memory is not integrated into the life story. Both are consistent with the alternative assumption that a critical component of PTSD is the development of the trauma into a landmark event so that the traumatic memory forms a reference point for the organization of other, non-traumatic experiences, and thereby a key to the understanding of oneself and others. In addition, Table 3 shows that participants with a PTSD symptom profile had more intrusive memories, had become more introverted in response to the trauma and felt that the traumatic event had had a more negative influence on their lives as compared to participants without the PTSD symptom profile. Seeking new and positive experiences, and thereby trying to avoid thinking of the trauma, had been a more predominant coping 
Table 3. Coping and integration of the traumatic memory in the PTSD symptom profile group and non-PTSD symptom profile group

\begin{tabular}{|c|c|c|c|c|c|c|c|}
\hline & \multicolumn{2}{|c|}{$\begin{array}{l}\text { PTSD symptom } \\
\text { profile }\end{array}$} & \multicolumn{2}{|c|}{$\begin{array}{c}\text { Non-PTSD } \\
\text { symptom profile }\end{array}$} & \multicolumn{3}{|c|}{$t$-tests } \\
\hline & $M$ & $S D$ & $M$ & $S D$ & $d f$ & $t$ & $p$ \\
\hline See connections & 3.95 & 0.87 & 2.37 & 1.29 & 103 & 5.50 & $<0.001$ \\
\hline Negative impact & 3.36 & 1.29 & 2.10 & 1.27 & 106 & 4.36 & $<0.001$ \\
\hline Intrusions & 3.76 & 1.05 & 2.82 & 0.97 & 106 & 4.00 & $<0.001$ \\
\hline Avoid thinking & 3.28 & 1.17 & 2.14 & 1.27 & 103 & 3.99 & $<0.001$ \\
\hline Inconsistencies & 2.56 & 1.01 & 1.61 & 1.38 & 104 & 3.68 & $<0.001$ \\
\hline My identity & 3.76 & 1.41 & 3.01 & 1.30 & 105 & 2.36 & $<0.05$ \\
\hline Introversion & 3.12 & 1.62 & 2.40 & 1.37 & 105 & 2.20 & $<0.05$ \\
\hline Elaborate & 3.56 & 1.35 & 4.02 & 1.18 & 104 & 1.65 & $=0.10$ \\
\hline Recovery & 2.44 & 1.22 & 2.18 & 1.19 & 103 & 0.92 & $=0.36$ \\
\hline Talking helped & 3.30 & 1.15 & 3.14 & 1.24 & 96 & 0.54 & $=0.59$ \\
\hline
\end{tabular}

strategy among participants with a PTSD symptom profile than among participants without. The former group had also perceived more inconsistencies between their own and other people's versions of the trauma. No significant differences were found on whether participants thought it was important to elaborate the trauma with themselves and others and as to whether they had benefited from talking about the trauma.

To rule out a possible bias in these results due to the fact that more persons in the PTSD symptom profile group had received therapeutic treatment, a series of multiple regression analyses was conducted. Each analysis included one of the variables listed in Table 3 as the dependent variable and PTSD symptom profile $(\mathrm{y} / \mathrm{n})$ and therapy $(\mathrm{y} / \mathrm{n})$ as the independent variables. The results are summarized in Table 4. PTSD symptom profile was a significant predictor for the top half of the dependent variables in Table 4. For three of these, therapy also showed significance, but at a much lower level. Therapy was the only significant predictor (at the 0.05 level) for 'Talking helped' and 'My identity'. However, for the latter, PTSD symptom profile also tended to be significant. For 'Avoid thinking' and 'Elaborate' therapy showed the opposite pattern as the PTSD symptom profile in that 'Avoid thinking'

Table 4. Summary of multiple regression analyses with PTSD-symptom profile and therapy as independent variables

\begin{tabular}{lccccrcr}
\hline & \multicolumn{3}{c}{ PTSD $(\mathrm{y} / \mathrm{n})$} & & \multicolumn{2}{c}{ Therapy $(\mathrm{y} / \mathrm{n})$} \\
\cline { 2 - 3 } Dependent var. & $d f$ & beta & $p$ & & beta & $p$ \\
\hline See connections & 101 & 0.42 & $<0.0001$ & & 0.22 & $<0.05$ \\
Negative impact & 104 & 0.39 & $<0.0001$ & & -0.03 & $=0.74$ \\
Intrusions & 104 & 0.31 & $<0.001$ & & 0.23 & $<0.05$ \\
Avoid thinking & 101 & 0.41 & $<0.0001$ & & -0.21 & $<0.05$ \\
Inconsistencies & 102 & 0.34 & $<0.001$ & & -0.00 & $=0.96$ \\
My identity & 106 & 0.17 & $=0.07$ & & 0.22 & $<0.05$ \\
Introversion & 103 & 0.17 & $=0.09$ & & 0.18 & $=0.07$ \\
Elaborate & 102 & -0.23 & $<0.05$ & & 0.25 & $<0.05$ \\
Recovery & 101 & 0.05 & $=0.59$ & & 0.15 & $=0.13$ \\
Talking helped & 99 & -0.00 & $=0.97$ & & 0.23 & $<0.05$ \\
\hline
\end{tabular}


was negatively related to therapy and 'Elaborate' positively related. It makes sense that persons who have had therapy would be more inclined to agree with the statement that it was important to elaborate what had happened with others and to disagree with the statement that the best thing to do was to avoid thinking of the trauma. For the other variables, therapy showed the same pattern as the PTSD symptom profile. One interpretation of this correspondence is that psychotherapy reinforces some of the coping strategies that persons with a PTSD symptom profile are already inclined to use (e.g. perceiving connections and similarities, ruminating about the trauma, seeing the trauma as central to one's identity). Another interpretation is that persons with such coping strategies were more inclined to seek psychotherapeutic treatment.

Finally, comparison of psychology students and folk high school students showed some differences on coping strategies: The folk high school students agreed more with the statement that they should seek new and positive experiences rather than think and talk about the trauma than did psychology students (means 2.9 versus $2.2 ; t(103)=2.6$, $p<0.05$ ), and had more observer perspective in their recollection of the trauma (means 2.6 versus $2.0, t(101)=2.1, p<0.05)$. Psychology students agreed more with the statement that the best thing to do was to talk with others and try to reach some understanding of what had happened (means 4.2 versus $3.3, t(104)=3.3, p<0.005$ ).

\section{Quantitative or qualitative differences? Comparisons of correlations}

We examined correlations separately in each group to see the extent to which relations among variables are different for participants with and without a PTSD symptom profile. By comparing correlations, we are able to see if the relations among variables (and not just the means) are different in the two groups. Comparisons of means and comparisons of correlations yield very different information and can be described as analyses of quantitative versus qualitative differences, respectively. If the means are higher in one group than in the other while the correlations are about the same, the difference between the groups can be described as a quantitative one in that the relations among variables are the same but one group just has more. In terms of an analysis of variance model, there would be a main effect but no interaction. If, on the other hand, the pattern of correlations are markedly different between the two groups, some underlying structural differences are indicated. The question of quantitative versus qualitative differences is a classical one in theories of psychopathology. Freud argued that only quantitative differences existed between neurotic individuals and persons without this diagnosis, for which reason studies of the neurotics would reveal general laws of the psychic apparatus. A similar view is sometimes found in relation to PTSD. For example, one might assume that individuals with a PTSD symptom profile simply have more and more intense (but not a different pattern of) post-traumatic reactions than persons with a trauma but no PTSD symptom profile. The description of PTSD offered by Horowitz (1986) and Horowitz and Reidbord (1992) is largely concerned with such quantitative differences between the pathological and non-pathological trauma reaction. Alternatively, the literature on dissociation often points to radically (qualitatively) different cognitive processes in the pathological case.

Though the question of quantitative or qualitative differences between pathological and non-pathological cases is a key issue in PTSD (as it is in most psychopathology), the technique of analysing correlations between groups to detect qualitative differences has not (as far as we know) been used before (see Rubin et al., 2002, for more details on this and related types of correlational analyses). We first present the similarities and then 
differences in the correlations calculated separately for each group. We used all 24 questions listed in the Appendix plus four scales from the Foa PSD test: trauma severity and the frequency of re-experience, avoidance, and arousal symptoms. Because of the large number of questions we must view these analyses as exploratory, and thus restrict ourselves to comparisons among simple correlations to search for similarities and differences among the two groups.

\section{Similarities}

The Posttraumatic Diagnostic Scale (Foa, 1995) contains measures of post-traumatic reactions, which are relatively highly correlated in each of the two groups, supporting the validity of the scale. Likewise, the memory questionnaire developed for the purpose of the present study contained three pairs of reversed questions (e.g. I became more introverted versus more extroverted), all of which were highly negatively correlated in both groups. In addition to such expected similarities, Table 5 shows that measures of recollective quality are strongly correlated in both groups, suggesting a common underlying dimension in each, rather than memories that are internally fragmented.

Table 6 shows all other correlations that are significant in both groups. The most important finding is a high positive correlation between the degree to which the trauma is seen as a part of personal identity and frequency of intrusive memories. Since intrusive memories are regarded as a defining feature of PTSD, this finding supports the assumption that a key component of PTSD is the development of the traumatic memory into a landmark in the autobiographical memory system. As such landmarks are highly accessible in memory and form reference points for the attribution of meaning to less salient events, this may in turn give way to intrusions and rumination. The degree to which the trauma is seen as a part of personal identity also correlates positively with the extent to which the trauma had violated participants' expectations in both groups. This is contrary to the idea that the trauma is hard to integrate into the life story and identity because it has violated basic assumptions of the self and the world (Janoff-Bulman, 1988).

Agreement with the statement 'I feel that what I had to do after the traumatic event was to elaborate what had happened with myself and others close to me' correlated positively

Table 5. Correlations between recollection qualities in the PTSD symptom profile group and the non-PTSD symptom profile group

\begin{tabular}{|c|c|c|c|c|c|c|c|}
\hline & PTSD & $\begin{array}{c}\text { Time } \\
\text { Travel }\end{array}$ & Emotion & Vision & $\mathrm{S} / \mathrm{T}$ & Audition & Bodily \\
\hline \multirow[t]{2}{*}{ Emotion } & Yes & $0.56^{* *}$ & & & & & \\
\hline & No & $0.69 * * *$ & & & & & \\
\hline \multirow[t]{2}{*}{ Vision } & Yes & $0.76^{* * *}$ & $0.59 * *$ & & & & \\
\hline & No & $0.63 * * *$ & $0.56^{* * *}$ & & & & \\
\hline \multirow[t]{2}{*}{ Smell-taste } & Yes & 0.37 & 0.28 & $0.47 *$ & & & \\
\hline & No & $0.47 * * *$ & $0.39 * * *$ & $0.42 * * *$ & & & \\
\hline \multirow[t]{2}{*}{ Audition } & Yes & $0.78 * * *$ & 0.37 & $0.66 * * *$ & $0.46^{*}$ & & \\
\hline & No & $0.51 * * *$ & $0.50 * * *$ & $0.59 * * *$ & $0.37 * *$ & & \\
\hline \multirow[t]{2}{*}{ Bodily } & Yes & $0.59 * *$ & $0.45^{*}$ & $0.58 * *$ & 0.32 & $0.43^{*}$ & \\
\hline & No & $0.45 * * *$ & $0.56^{* * *}$ & $0.32 * *$ & $0.30 * *$ & $0.51 * * *$ & \\
\hline \multirow[t]{2}{*}{ Video-like } & Yes & $0.74 * * *$ & $0.41 *$ & $0.67 * * *$ & 0.34 & $0.54 * *$ & $0.57 * *$ \\
\hline & No & $0.65 * * *$ & $0.56^{* * *}$ & $0.58 * * *$ & $0.41 * * *$ & $0.50 * * *$ & $0.38 * * *$ \\
\hline
\end{tabular}

PTSD symptom profile, Yes $(n=24-25)$, No $(n=80-81)$.

$* p<0.05 ; * * p<0.01 ; * * * p<0.001$. 
Table 6. Correlations are significant in both the PTSD symptom profile group and non-PTSD symptom profile group

\begin{tabular}{llcc}
\hline Variable 1 & Variable 2 & PTSD & Non-PTSD \\
\hline Trauma has become part of my identity & Present life suddenly evokes & $0.48^{*}$ & $0.38^{* * *}$ \\
& my memory & & \\
Trauma has become part of my identity & I never imagined it could happen & $0.50^{*}$ & $0.23^{*}$ \\
Positive impact on personal development & Elaborate ... with self and others & $0.43^{*}$ & $0.26^{*}$ \\
Discussing adds distance \& perspective & Elaborate ... with self and others & $0.50^{*}$ & $0.34^{* *}$ \\
Discussing adds distance \& perspective & Inconsistencies in my \& others' & $0.43^{*}$ & $0.31^{*}$ \\
& memory & & \\
Recovered new aspects by talking & Inconsistencies in my \& others' & $0.56^{* *}$ & $0.44^{* * *}$ \\
& memory & & \\
\hline
\end{tabular}

PTSD symptom profile group $(n=21-25)$.

Non-PTSD symptom profile group $(n=74-81)$.

$* p<0.05 ; * * p<0.01 ; * * *<0.001$.

with the degree to which the trauma was seen to have had a positive impact on the person's life and also with the agreement expressed to the statement: 'By discussing the traumatic event with others, I have managed to distance myself to the event and look at it in another way.' Apparently, participants in both groups have benefited from talking to others about the traumatic event. Also, positively associated to discussing the trauma with others is the discovery of inconsistencies between their own and other people's version of the trauma. Finally, the discovery of inconsistencies is also positively associated with recovering new aspects of the traumatic event.

\section{Differences}

Some correlations were markedly different between the two groups. This shows that the two groups varied not just in the amount of post-traumatic reaction (as evidenced by the comparisons of means), but also qualitatively in the pattern of reactions. Table 7 shows all the correlations that are significantly different between the two groups at least the 0.05 level. In all cases except one, the individual correlations are only significantly different from zero in the PTSD symptom profile group. By and large the differences between the correlations in the two groups indicate that the two groups have employed different coping strategies in response the trauma. In suggesting more detailed explanations for each of these specific pairs of correlations, we start with the group that has the higher correlation and discuss the pairs in the same order as they appear in Table 7.

The existence of a larger correlation between trauma severity and degree of memory fragmentation in the PTSD profile group can be seen to support the idea of primary dissociation in PTSD. The larger negative correlation between frequency of avoidance symptoms and degree of field perspective in the PTSD profile group points in a similar direction, since a reduced field perspective can be taken to indicate reduced emotional reliving, (Nigro \& Neisser, 1983; Robinson, \& Swanson, 1993; Teufel, unpublished manuscript, 2000). The degree to which inconsistencies have been seen between ones own and other people's memory of the trauma correlates more highly with three measures of recollective quality (relive bodily impressions, relive visual impressions, recollect accurately as a video) in the PTSD symptom profile group. More detailed and vivid memories can support both more accuracy and inaccuracy, both of which may lead to the observation of inconsistencies between one's own and other people's memory. However, since these 
Table 7. Correlations are different from each other in the PTSD symptom profile group and nonPTSD symptom profile group

\begin{tabular}{|c|c|c|c|}
\hline Variable 1 & Variable 2 & PTSD & Non-PTSD \\
\hline Trauma severity & $\begin{array}{l}\text { Memory is fragmentated not } \\
\text { coherent }\end{array}$ & 0.51 & $0.01 *$ \\
\hline Frequency of avoidance symptoms & $\begin{array}{l}\text { I recall event seen through } \\
\text { my own eyes }\end{array}$ & -0.58 & $-0.04 *$ \\
\hline I would think as little as possible of it & I recollect the visual impressions & 0.58 & $-0.05 * *$ \\
\hline Inconsistencies in my \& others' memory & I recollect the bodily impressions & 0.52 & $-0.02 *$ \\
\hline Inconsistencies in my \& others' memory & I recollect the visual impressions & 0.49 & $-0.14 * *$ \\
\hline Inconsistencies in my \& others' memory & $\begin{array}{l}\text { I recollect accurately as a video } \\
\text { record }\end{array}$ & 0.57 & $-0.11 * *$ \\
\hline Discussing adds distance $\&$ perspective & $\begin{array}{l}\text { Present life suddenly evokes my } \\
\text { memory }\end{array}$ & -0.61 & $0.12^{*}$ \\
\hline I recovered new aspects by talking & I became more introverted & -0.43 & $0.17 *$ \\
\hline I recovered new aspects by talking & $\begin{array}{l}\text { Trauma has become part of my } \\
\text { identity }\end{array}$ & -0.22 & $0.48 * *$ \\
\hline
\end{tabular}

PTSD symptom profile group $(n=22-25)$.

Non-PTSD symptom profile group $(n=75-82)$.

$* p<0.05$ and $* * p<0.01$.

correlations are only present in the PTSD symptom profile group they can be seen as pointing in the same direction as the previously mentioned ones: recollecting the trauma instigates some sort of avoidance of the full scenario of the memory among individuals with a PTSD symptom profile. Discussing the traumatic event with others and thereby coming to look at it with a different perspective correlates more negatively with ratings of intrusive memories in the PTSD symptom profile group. Similarly, becoming aware of new aspects of the trauma in conversations correlates more negatively with the extent to which the person became more introverted after the trauma in the PTSD symptom profile group. Of course, these relations are two-faced. They also mean that not sharing the trauma with others is positively related to frequency of intrusions and to degree of introversion in the PTSD symptom profile group. Finally, Table 7 shows a larger correlation in the non-PTSD profile group between discovering new aspects of the trauma via social interaction and classifying the trauma as part of personal identity. This may indicate a more elaborate narrative integration of the trauma among participants in the non-PTSD profile group as compared to participants in the PTSD profile group.

All of these interpretations are post hoc and somewhat speculative and should be considered with that reservation in mind. However, a consistent pattern emerging from the findings presented in Table 7 seems to be that participants with a PTSD symptom profile show more attempts at avoiding conscious reliving of the trauma memory as a function of trauma severity and strength of the traumatic recollection. Such a relation is not found in the non-PTSD symptom profile group. We may therefore conclude that qualitative differences appear to exist in the pattern of post-traumatic reactions in the two groups.

\section{DISCUSSION}

Before turning to a discussion of the findings, some caveats in the interpretation of the results need to be mentioned. First, the study should be replicated, especially with clinical 
populations, before practical implications can be drawn. Second, the traumas reported in the present study were widely different and though none of the reported trauma categories were significantly different from the rest on the prevalence of the PTSD symptom profile, it is not clear whether their heterogenous nature has affected the results. Third, the participants were young students, and it remains to be clarified whether the results can be generalized to a different population, such as older persons, who may have different coping strategies (cf. Berntsen \& Rubin, 2002).

The main findings support the assumption that memories of traumatic events form vivid landmarks in autobiographical memory as well as the related assumption that this reference point effect is stronger for individuals with a PTSD symptom profile than for individuals without. These findings are at odds with the idea that a lack of integration of the traumatic memory in the autobiographical memory system is a key component of PTSD. Contrary to what has been claimed in some of the clinical literature, the voluntarily retrieved, conscious recollection of the trauma was not impaired in the PTSD symptom profile group relative to the non-PTSD symptom profile group. In fact, exactly the opposite was found.

Participants with a PTSD symptom profile reported more vivid recollections of the traumatic event in terms of more intense reliving on sensory modalities and emotion. They also perceived more connections and similarities between the trauma and current events in their daily life than did the participants without a PTSD symptom profile. Furthermore, participants with a PTSD symptom profile agreed more with the statement that the trauma had become part of their identity. The development of the traumatic memory into a key event for the person's life story and identity renders the memory highly accessible, which may, in turn, explain why participants with a PTSD symptom profile reported more intrusive memories than participants without. This suggestion is supported by a positive correlation in both groups between frequency ratings of intrusive memories and the degree to which the trauma was seen as a central part of the person's identity. The fact that the amount of emotions (fear and helplessness) experienced during the trauma was higher for participants with a PTSD symptom profile than for participants without is consistent with the landmark assumption. According to a standard cognitive view, memories for highly emotionally arousing events are better encoded and consolidated than less emotional memories, due to their distinctiveness, personal importance, emotional intensity and corresponding release of stress hormones during encoding (Cahill \& McGaugh, 1998). They are often thought about and become connected to other memories by multiple links in an associative network. Due to their distinctiveness and personal significance, they often serve as reference points for the organization of other personal experiences and thus become important components of the life story and personal identity. Among Vietnam veterans with severe PTSD, findings that are consonant with this interpretation have been reported by McNally et al. (1995). They found that veterans with PTSD who were still wearing their regalia recorded more memories of their time in Vietnam and more overgeneral (non-specific) memories in response to both positive and negative cue words than did veterans with PTSD who were not wearing regalia. As wearing regalia indicates persistent identification with the role as a soldier, the findings from McNally et al. point in the same direction as the findings reported here. Trauma memories form reference points for the attribution of meaning to other parts of the life story.

On the other hand, the differences between the correlations in the two groups in Table 7 support the insight of many clinicians that qualitatively different processes take place in PTSD. The comparisons of correlations in the two groups indicated that participants with a PTSD symptom profile showed more dissociation and attempts at avoiding conscious 
reliving of the trauma memory as a function of trauma severity and strength of the traumatic recollection. Such a pattern was not present in the non-PTSD symptom profile group. Increased avoidance and dissociation in the PTSD symptom profile group was further supported by a more frequent use of an observer perspective in recollecting the trauma in this group relative to the non-PTSD group. This is also in agreement with the landmark explanation. Increased access to the trauma memory and it role as a landmark leads to vivid and intrusive memories and over-inclusive classifications of other nontraumatic memories as related to the trauma. This is likely to generate a need by the traumatized person for distancing him- or herself from the phenomenologically painful reliving and thus motivate the use of an observer perspective in remembering.

Insights from both the clinical and the autobiographical memory literatures are needed to make sense of the findings: traumatic memories seem to form landmarks and at the same time they seem to be subject to processes of dissociation and/or avoidance. We suggest the following synthesis between the two views. Instead of speaking of a lack of integration of the trauma in the overall life story, it seems more precise to speak of a dysfunctional integration, according to our results. By dysfunctional integration we mean an integration of the trauma into the life narrative, which gives way to over-inclusive classifications of non-traumatic, personal memories as being similar or thematically related to the trauma (see also Berntsen, 2001; Ehlers \& Clarke, 2000). Having a traumatic memory as a central component of the life story and personal identity may simply be harmful to a person's well-being. The traumatic memory may be too dominant in the organization of the life-story and in the attribution of meaning to old and new, non-traumatic experiences. The end product for the PTSD symptom profile group may be described as exactly the fluctuation between reliving and avoidance symptoms that is regarded as central for the diagnosis of PTSD (American Psychiatric Association, 1994; Horowitz \& Reidbord, 1992). However, this fluctuation is due not to a disintegration of the trauma in autobiographical memory, according to this alternative interpretation, but to a dysfunctional reference point effect so that the trauma is remembered too well and too often and is too frequently referred to in the process of ascribing meaning to surrounding memories and generating expectations for the future.

\section{ACKNOWLEDGEMENTS}

The study was supported by a grant from the Danish Research Council for the Humanities.

\section{REFERENCES}

American Psychiatric Association (1994). Diagnostic and statistic manual of mental disorders (4th ed.). Washington, DC: American Psychiatric Association.

Amir, N., Stafford, J. Freshman, M. S., \& Foa, E. B. (1998). Relationship between trauma narratives and trauma pathology. Journal of Traumatic Stress, 11, 385-392.

Berntsen, D. (1996). Involuntary autobiographical memories. Applied Cognitive Psychology, 10, 435-454.

Berntsen, D. (1998). Voluntary and involuntary access to autobiographical memory. Memory, 6, 113-141.

Berntsen, D. (2001). Involuntary memories of emotional events. Do memories of traumas and extremely happy events differ? Applied Cognitive Psychology, 15, 135-158.

Berntsen, D., \& Rubin, D. C. (2002). Emotionally charged memories across the life span: the recall of happy, sad, traumatic, and involuntary memories. Psychology of Aging, 17, 636-652. 
Brewer, W. F. (1992). The theoretical and empirical status of the flashbulb memory hypothesis. In E. Winograd, \& U. Neisser (Eds.), Affect and accuracy in recall. Studies of 'flashbulb' memories (pp. 274-305). New York: Cambridge University Press.

Brewer, W. F. (1996). What is recollective memory? In D. C. Rubin (Ed.), Remembering our past: Studies in autobiographical memory (pp. 19-66). Cambridge: Cambridge University Press.

Brewin, C. R. (2001). Memory processes in post-traumatic stress disorder. International Review of Psychiatry, 13, 159-163.

Brewin, C. R., Christoulides, J., \& Hutchinson, G. (1996). Intrusive thoughts and intrusive memories in a nonclinical sample. Cognition and Emotion, 10, 107-112.

Brewin, C. R., Dalgleish, T., \& Joseph, S. (1996). A dual representation theory of Posttraumatic Stress Disorder. Psychological Review, 103, 670-686.

Cahill, L., \& McGaugh, J. L. (1998). Mechanisms of emotional arousal and lasting decarative memory. Trends in Neuroscience, 21, 294-299.

Christianson, S.- $\AA$. (Ed.). (1992). The handbook of emotion and memory. Research and theory. Hillsdale, NJ: Erlbaum.

Ehlers, A., \& Clark, D. M. (2000). A cognitive model of posttraumatic stress disorder. Behavior Research and Therapy, 38, 319-345.

Ericsson, K. A., \& Simon, H. A. (1993). Protocol analysis: Verbal reports as data (rev. ed.). Cambridge, MA: MIT (Bradford Books).

Foa, E. B. (1995). Posttraumatic Stress Diagnostic Scale (PDS). Minneapolis: National Computer Systems.

Foa, E. B., Molnar, C., \& Cashman, L. (1995). Change in rape narratives during exposure therapy for Posttraumatic Stress Disorder. Journal of Traumatic Stress, 8, 675-690.

Frank., M. G., \& Gilovich, T. (1989). Effects of memory perspective on retrospective causal attributions. Journal of Personality and Social Psychology, 9, 17-31

Freud, S. (1899/1953). Screen memories. In J. Strachey (Ed.), Sigmund Freud: Collected papers, 5, 47-69, London: Hogarth Press.

Horowitz, M. J. (1975). Intrusive and repetitive thought after experimental stress. Archives of General Psychiatry, 32, 1457-1463.

Horowitz, M. J. (1986). Stress Response Syndromes (2nd ed.). Northvale, NJ: Jason Aronson.

Horowitz, M. J., \& Reidbord, S. P. (1992). Memory, emotion, and response to trauma. In S.-A. Christianson (Ed.), The handbook of emotion and memory. Research and theory (pp. 343-357). Hillsdale, New Jersey: Lawrence Erlbaum.

Janoff-Bulman, R. (1988). Assumptive worlds and the stress of traumatic events: applications of the schema construct. Social Cognition, 7, 113-136.

Johnson, M. (1988). Reality monitoring: an experimental phenomenological approach. Journal of Experimental Psychology:General, 117, 390-394.

Larsen, S. F. (1998). What is it like to remember? On phenomenal qualities of memory. In C. P. Thompson, D. J. Herrman, D. Bruce, J. D. Read, D. G. Payne, \& M. P. Toglia (Eds.), Autobiographical memory. Theoretical and applied perspectives (pp. 163-190). Mahwah, NJ: Erlbaum.

McNally, R. J. (1998). Experimental approaches to cognitive abnomality in Posttraumatic Stress Disorder. Clinical Psychological Review, 18, 971-982.

McNally, R. J., Lasko, N. B., Macklin, M. L., \& Pitman, R. K. (1995). Autobiographical memory disturbance in combat-related Post-Traumatic Stress Disorder. Behavioral Research and Therapy, $33,619-630$.

Neisser, U. (1982). Snapshots or benchmarks? In U. Neisser (Ed.), Memory observed: Remembering in natural contexts (pp. 43-48). San Francisco: Freeman.

Nemiah, J. C. (1998). Early concepts of trauma, dissociation and the unconscious: their history and current implications. In J. D. Bremner, \& C. R. Marmar (Eds.), Trauma, memory and dissociation (pp. 1-21). Washington, DC: American Psychiatric Press.

Nigro, G., \& Neisser, U. (1983). Point of view in personal memories. Cognitive Psychology, 15, 467-482.

Nijenhuis, E. R. S., \& van der Hart, O. (1999). Forgetting and reexperiencing trauma. In J. Goodwin, $\&$ R. Cittias (Eds.), Splintered reflections: Images of the body in the trauma (pp. 39-65). New York: Basic Books.

Pillemer, D. B., Goldsmith, L. R., Panter, A. T., \& White, S. H. (1988). Very long-term memories of the first year in college. Journal of Experimental Psychology: Learning, memory and Cognition, 14, 709-715. 
Robinson, J. A. (1992). First experiences: contexts and functions in personal histories. In M. A. Conway, D. C. Rubin, H. Spinnler, \& W. Wagenaar (Eds.), Theoretical perspectives on autobiographical memory (pp. 223-239). Utrecht: Kluwer Academic Publishers.

Robinson, J. A., \& Swanson, K. L. (1993). Field and observer modes of remembering, Memory, 1, 169-184.

Rubin, D. C., \& Kozin, M. (1984). Vivid memories. Cognition, 16, 81-95.

Schelach, L., \& Nachson, I. (2001). Memory of Auschwitz survivors. Applied Cognitive Psychology, $15,119-132$.

Shum, M. S. (1998). The role of temporal landmarks in the autobiographical memory processes. Psychological Bulletin, 124, 423-442.

Tromp, S., Koss, M. P., Figueredo, A. J., \& Tharan, M. (1995). Are rape memories different? A comparison of rape, other unpleasant and pleasant memories among employed women. Journal of Traumatic stress, 8, 607-627.

Van der Hart, O., van der Kolk, B. A., \& Boon, S. (1998). Treatment of dissociative disorders. In J. D. Bremner, \& C. R. Marmar (Eds.), Trauma, memory and dissociation (pp. 253-283). Washington, DC: American Psychiatric Press.

Van der Kolk, B. A., \& Fisler, R. (1995). Dissociation and the fragmentary nature of traumatic memories: overview and exploratory study. Journal of Traumatic Stress, 8, 505-525.

Vasterling, J. J., Brailey, K., Constans, J. I., \& Sutker, P. B. (1998). Neuropsychology, 12, 125-133.

Wagenaar, W. A., \& Groeneweg, J. (1990). The memory of concentration camp survivors. Applied Cognitive Psychology, 4, 77-87.

Wheeler, M. A., Stuss, D. T., \& Tulving, E. (1997). Toward a theory of episodic memory: the frontal lobes and autoneutic consciousness. Psychological Bulletin, 121, 331-354.

\section{APPENDIX MEMORY QUESTIONNAIRE}

1. Have you received therapeutic treatment in relation to the trauma?

$$
\text { Yes__ No__ }
$$

In the following some questions related to the traumatic event are listed. For each question, circle the number that corresponds to your estimation.

2. After the traumatic event I became more extroverted and more interested in reaching-out in my relationship to others.

Totally disagree 12345 Totally agree

3. After the traumatic event I became more introverted and less interested in reaching out for other people.

Totally disagree 12345 Totally agree

4. Seen in relation to the person I am today, I feel that the traumatic event has had a predominantly positive influence on my personal development.

Totally disagree 12345 Totally agree

5. Seen in relation to the person I am today, I feel that the traumatic event has had a predominantly negative influence on my personal development.

Totally disagree 12345 Totally agree

6. I feel that what I had to do after the traumatic event was to think as little as possible of it and instead try to get some good experiences.

Totally disagree 12345 Totally agree

7. I feel that what I had to do after the traumatic event was to elaborate what had happened with myself and others close to me.

Totally disagree 12345 Totally agree

8. I feel that the traumatic event has become part of my identity

Totally disagree 12345 Totally agree

9. I automatically see connections and similarities between the traumatic event and experiences in my present life.

Never 12345 Very often 
10. Things that are happening in my present life may unexpectedly evoke my memory of the traumatic event or parts of it.

Never 12345 Very often

11. Before the traumatic event I would never have imagined that such a thing could happen to me. Totally disagree 12345 Totally agree

12. I have experienced inconsistencies between my memory of the traumatic event and others' (for example witnesses') descriptions of what actually happened.

Never 12345 Very often

13. By discussing the traumatic event with others, new aspects of the traumatic event have come to my mind.

Never 12345 Very often

14. By discussing the traumatic event with others, I have managed to distance myself to the event and look at it in another way.

Totally disagree 12345 Totally agree

To prepare yourself for the following questions, please recall the traumatic event, see it with your mind's eye, and on basis of that answer the questions.

15. When I recall the traumatic event, it is like I am travelling in time and relive the event all over again.

Not at all 12345 As clearly as if it is going on now

16. When I recall the traumatic event, I relive the emotions I had when the event took place.

Not at all 12345 As clearly as if it is going on now

17. When I recall the traumatic event, I relive the visual impressions I had when the event took place.

Not at all 12345 As clearly as if it is going on now

18. When I recall the traumatic event, I relive the smell and taste sensations I had when the event took place.

Not at all 12345 As clearly as if it is going on now

19. When I recall the traumatic event, I relive the sound impressions I had when the event took place.

Not at all 12345 As clearly as if it is going on now

20. When I recall the traumatic event, I relive the bodily sensations I had when the event took place.

Not at all 12345 As clearly as if it is going on now

21. When I recall the traumatic event, it seems to me that the memory reproduces the event precisely as it happened - just like a video recording.

Not at all 12345 As clearly as if it is going on now

22. When you recall the traumatic event, do you then think of it as a continuous series of episodes or as some isolated incoherent fragments?

Totally incoherent 12345 Totally coherent

The following two questions have to do with the perspective of the memory: When you recall what happened, do you then reexperience the event as seen through your own eyes, or do you see yourself from outside in the memory image:

23. When I now recall the traumatic event I mainly see what happened as seen through my own eyes.

Totally disagree 12345 Totally agree

24. When I now recall the traumatic event, I mainly see what happened as if I saw it through a spectator's eyes.

Totally disagree 12345 Totally agree 